\title{
Failure of preventive treatments in migraine: an observational retrospective study in a tertiary headache center
}

\author{
Marianna Delussi", Eleonora Vecchio, Giuseppe Libro, Silvia Quitadamo and Marina de Tommaso(B)
}

\begin{abstract}
Background: Although the criteria for acute migraine treatment and prevention have been well described, there are still unmet needs, general underuse and low benefits of preventive drugs.

The aim of the present study was to retrospectively observe the short-term effect of preventive treatment in a cohort of migraine patients attending a tertiary headache center, using data from electronic medical records.

Methods: This was an observational retrospective cohort study based on data collected in a tertiary headache center. Data were extracted from an electronic dataset collected from January 2009 to December 2019. The main selection criteria were as follows: age of 18-75 years; diagnosis of migraine without aura (MO), migraine with aura (MA) or chronic migraine (CM); a control visit 3 months after the first access; and prescription of preventive treatment with level of evidence 1 as reported by Italian guidelines. As the primary outcome, we considered the change in the frequency of headache at the follow-up visit. Then, as secondary outcome measures, we used disability scores, intensity of headache, and allodynia. As predictive factors, we considered age, migraine duration, sex, headache frequency, allodynia, anxiety and depression at baseline, and comorbidity with fibromyalgia.
\end{abstract}

Results: Among the 6430 patients screened, 2800 met the selection criteria, 1800 returned to the follow-up visit, 550 withdrew because of adverse events, and 1100 were included the analysis. One hundred thirty-four patients had a frequency reduction of 50\% or more. Flunarizine was used for less severe migraine, with a better effect compared to those of other drugs (odds ratio: 1.48; p: 0.022). Low headache frequency and absent or mild allodynia predicted a better outcome.

Conclusions: The mild effect of preventive drugs on migraine features and even the number of patients who were lost to follow-up or dropped out because of adverse events confirm that in severe and chronic patients, the first line of prevention can only delay a more focused therapeutic approach.

Keywords: Migraine, Preventive treatment, Observational study, Tertiary headache center

\footnotetext{
* Correspondence: marina.detommaso@uniba.it

Applied Neurophysiology and Pain Unit, Basic Medical Sciences,

Neuroscience and Sensory System Department-SMBNOS, Bari Aldo Moro

University, Policlinico General Hospital, Giovanni XXIII Building, Via Amendola

207, A 70124 Bari, Italy
}

C C The Author(s). 2020 Open Access This article is licensed under a Creative Commons Attribution 4.0 International License, which permits use, sharing, adaptation, distribution and reproduction in any medium or format, as long as you give appropriate credit to the original author(s) and the source, provide a link to the Creative Commons licence, and indicate if changes were made. The images or other third party material in this article are included in the article's Creative Commons licence, unless indicated otherwise in a credit line to the material. If material is not included in the article's Creative Commons licence and your intended use is not permitted by statutory regulation or exceeds the permitted use, you will need to obtain permission directly from the copyright holder. To view a copy of this licence, visit http://creativecommons.org/licenses/by/4.0/. The Creative Commons Public Domain Dedication waiver (http://creativecommons.org/publicdomain/zero/1.0/) applies to the data made available in this article, unless otherwise stated in a credit line to the data. 


\section{Background}

Migraine is a common and disabling disease, affecting approximately $12-14 \%$ of the occidental population [1]. Despite the criteria of acute episodes, treatment and prevention having been well described [2], there is still a large proportion of patients with unmet needs, general underuse and low benefits of preventive treatments [3]. National guidelines indicate the conditions for the prescription of preventive treatment, the drugs with evidence of action and consequent recommendations for their use [2]. Real-world studies have reported the modality of preventive treatment prescription for general practitioners and neurologists. An observational study in the U.S. included 43,660 migraine patients receiving different preventive drugs in addition to acute treatment [4]. The study identified the main comorbidities associated with preventive drug prescription, such as sleep disorders in females, but there are no data on specific treatments and their effects. The French SMILE study assessed the determinants of the prescription of migraine preventive therapy by GPs and neurologists and factors determining eligibility, such as the frequency and severity of headache and scarce evidence of the efficacy of acute treatment [5]. An Italian study evaluating the use of triptans showed that only $21.3 \%$ of patients using triptans were under oral preventive treatment or botulin toxin treatment. In the same population, amitriptyline was the most prescribed drug, followed by topiramate (6.3\%), propranolol (3.3\%) and atenolol (2.7\%). The rate of improvement was estimated on the basis of the reduction in triptan use; the use of triptans was even significantly lower among subjects treated with oral preventive therapies than among those without these drugs, though mild improvement was present in the group with chronic migraine [3]. The study underlined that the current use of preventive therapies is limited and has negligible benefits and that most migraine patients currently have unmet needs.

Few data are available about preventive treatment prescriptions and their efficacy in patients observed at third-level headache centers. Such data could potentially be useful for understanding the utility of available preventive drugs and the real need for new drugs for migraine prevention [6].

The aim of the present study was to retrospectively observe the short-term effect of preventive treatment in a cohort of migraine patients attending a tertiary headache center, using data from electronic medical records.

\section{Methods}

\section{Study design}

This was an observational retrospective cohort study based on data collected in a tertiary headache center.

\section{Setting}

The Applied Neurophysiology and Pain Unit (ANPlab) includes three neurologists, two psychologists and one nurse. All patients are asked to keep a headache diary at the time of booking the first visit (which precedes the first access by approximately 3 months) and to return 3 months later for a follow-up visit, regardless of the prescription of preventive treatment.

An example of a headache diary used by patients is reported in Supplementary Fig. 1. The diary includes the allodynia scale with scores from 0 to 12 , according to previous studies [7].

Only a limited number of clinical features are converted into electronic codes useful for retrospective analysis.

The local Ethics Committee of Bari Policlinico General Hospital approved the use of the electronic database, and patients signed an informed consent form about the inclusion of their data and use for scientific purposes.

\section{Participants}

The present data were extracted from an electronic dataset collected from January 2009 to December 2019.

For the present analysis, we selected patients aged 1875 years; who received a diagnosis of migraine without aura (MO), migraine with aura (MA) or chronic migraine $(C M)[8,9]$; who were currently free from preventive treatments and the use of central nervous system-targeting drugs; who had had a control visit 3 months after the first access; and who were prescribed preventive treatment with level of evidence 1 as reported by Italian guidelines [2]. We did not select patients with severe general medical comorbidities, such as hepatic, renal and cardiovascular insufficiency; previous or current neurologic diseases beside migraine; or a diagnosis of current or previous psychiatric diseases. Exposure All the preventive drugs with level of evidence 1, including antidepressants (amitriptyline), beta-blockers (propranolol and atenolol), calcium channel blockers (flunarizine), and antiepileptic drugs (topiramate), were initially considered together and later analyzed individually in subgroups treated with the respective drugs. Meanwhile, data analysis was performed, and we noted that for a subgroup of patients who specifically denied the use of drugs in a first attempt, magnesium was prescribed. In another subgroup, clinicians opted for the use of candesartan because of the presence of hypertension and contraindication to the use of beta-blockers. In the final analysis, we thus decided to also include the patients described above, although neither treatment was included in the list of drugs with level of evidence I. Considering that valproate is not indicated in Italy for the treatment of migraine, clinicians prescribed topiramate as the first preventive drug. Other drugs with level 
of evidence II, such as gabapentin, pizotifen, and dihydroergotamine, were not used as primary preventive treatments [2].

\section{Variables}

As a primary outcome measure for the effect of preventive treatment, we considered the change in the frequency of headache at follow-up. As secondary outcomes, we used the MIDAS score [10], the intensity of headache on a 0 10 scale, allodynia [7] and general quality of life [11]. For headache frequency, we considered the average number of headache days per month over the last 3 months. As predictive factors for headache frequency reduction, we considered age, gender, duration of headache, frequency and intensity of headache, allodynia, and anxiety and depression scores as observed at the first access $[12,13]$. Comorbidity with fibromyalgia was also considered, as the center has specific experience with this condition [14]. The lack of distinction between headache and migraine days could be potentially confusing for the evaluation of the outcome; this feature was introduced as an option in the electronic database over the course of clinical activity. Another confusing factor could be FM comorbidity, which could have influenced the choice of preventive treatment. A source of potential bias is the unpredictable number of patients lost to follow-up, the low reliability of headache diaries, and the choice of treatments other than those recommended as first-line drugs, which may happen in clinical practice. Another bias could be the lack of data about the number of migraine days and the number of analgesics used. Data on symptomatic drugs and their effects are missing because of a problem in the electronic database occurring from 2009 to 2016.

Patients with missing data for the variables considered primary and secondary outcome measures were not considered in the present analysis.

\section{Statistical analysis}

Considering that an average reduction in migraine frequency of approximately $50 \%$ is generally indicated as a good outcome and that a reduction lower than $30 \%$ could be interpreted as treatment failure, we assessed a minimum sample size of 459 patients to explore the general effect of preventive treatments ( $\beta$ of $0.20-80 \%$, power of $\alpha$ i $0.05)$. This was valid for the entire migraine group.

Preliminarily, univariate ANOVA was performed for the primary variable, comparing the percent change in headache frequency among single migraine types and drug subgroups. The number of cases with a $50 \%$ change in migraine frequency was computed for the whole group and in each subgroup treated with a specific drug, thus computing the odds ratio to establish the superiority of a drug within the whole migraine group. Multivariate ANOVA was also performed to assess the changes in secondary outcome variables among migraine types and preventive treatments. A multivariate linear regression analysis between the percent change in the primary outcome measure and predictive factors was then performed. We also computed the odds ratio for the primary outcome, considering gender, presence of allodynia and comorbidity with fibromyalgia.

\section{Results}

\section{Demographic data for selected patients}

The flowchart depicting patient selection is shown in Fig. 1. Among a total of 4480 migraine patients with highmedium headache frequency, 2800 met the selection criteria, while 550 were under current or had previously received preventive treatments; 320 were using CNStargeting drugs for psychiatric comorbidity; 540 reported other primary headaches in association with migraine such as tension-type headache or primary stabbing headache; 102 had other neurological diseases, such as multiple sclerosis, polyneuropathies, previous cerebrovascular disorders, dementia and myasthenia; and the remainder were affected by severe general medical diseases (Fig. 1). Two hundred fifty-five patients used triptans for symptomatic treatment, and the remaining patients used NSAIDS. All patients were given suggestions to take triptans and/or NSAIDs (400$600 \mathrm{mg}$ of ibuprofen) for migraine attacks. Patients with medication overuse were requested to replace the abused drug and to seek symptomatic therapy only in cases of severe headache.

The demographic and main clinical data are reported in Table 1. Patients who dropped out because of adverse events were similar in age and sex to the selected group (38.12 $\pm 12.1 ; 135$ males). The adverse effects of topiramate were sedation (225 patients), paresthesia (24 patients) and weight loss (1 patient); those for amitriptyline were sedation (150 patients), tachycardia and arrhythmia (15 patients), irritability and insomnia (15 patients) and weight gain (20 patients); those for flunarizine were weight gain (55 patients) and sedation (15 patients); those for beta-blockers were hypotension and bradycardia (24 cases); and those for magnesium were gastrointestinal symptoms (6 patients). No patients requested hospitalization. Among the 296 patients with chronic migraine, 202 reported the use of more than 10 monthly doses of NSAIDs, so they received a diagnosis of medication-overuse headache (MOH) [9]. CM patients presented with older age and higher anxiety and depression scores than the other participants (Table 1).

Table 2 reports the preventive treatments used by all patients. Fifty patients who were treated with antidepressants, 66 with antiepileptics, 2 with beta-blockers, 5 with calcium channel blockers and 1 with sartans reported slight side effects and did not request drug suspension. Eight hundred and twenty patients used triptans with 


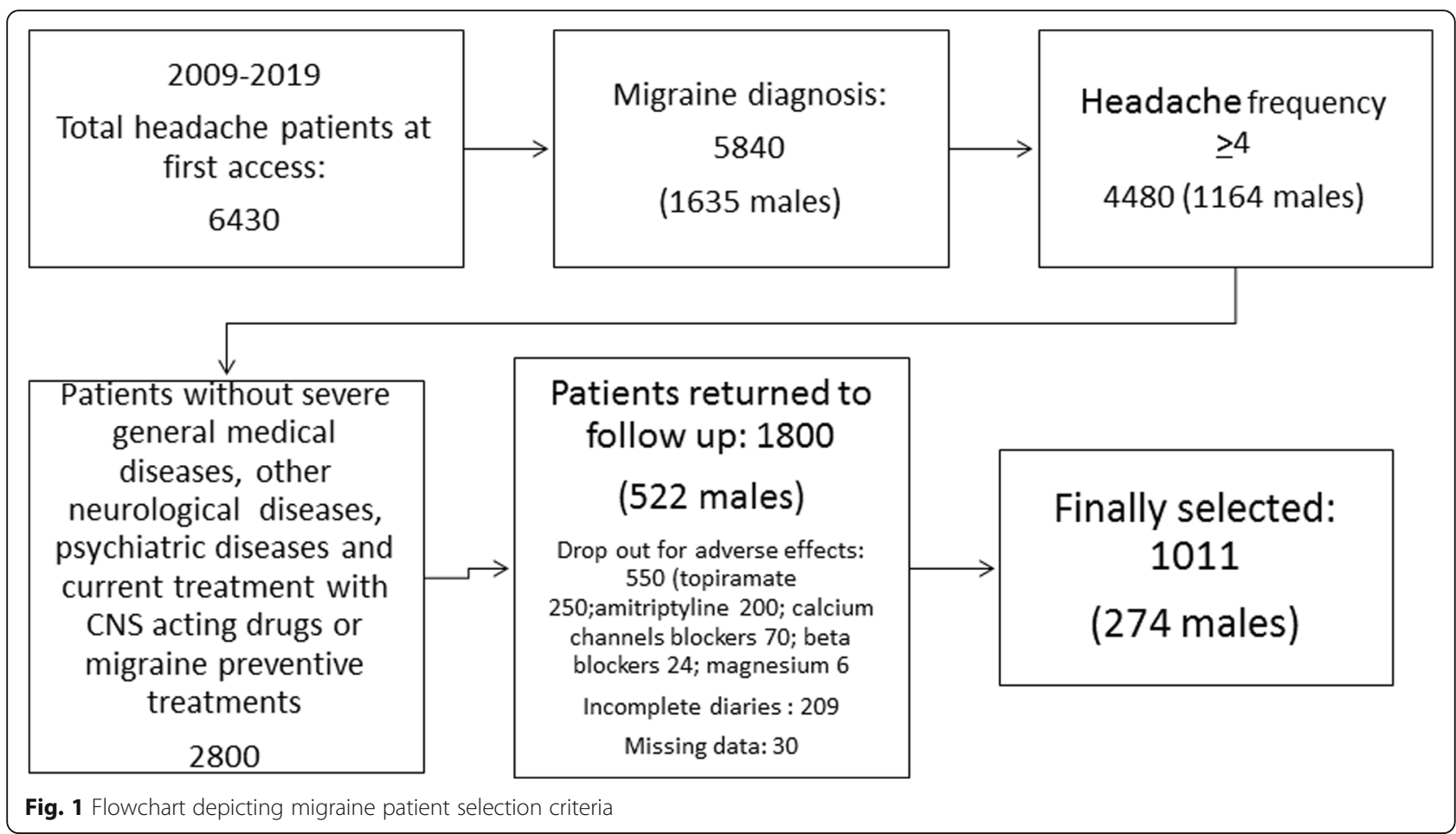

good effects; 220 continued to use NSAIDs, while in the remaining patients, neither drug was efficacious.

The average frequency of migraine at baseline differed among the drugs prescribed: it was higher in the groups treated with antiepileptics and antidepressants than in the other groups, excluding the group prescribed sartans (Table 3). For 154 females presenting with FM comorbidity, neurologists suggested amitriptyline in 104 cases, topiramate in 25 cases, flunarizine in 5 cases, propranolol in 2 cases, magnesium in 2 cases and sartans in 3 cases. Amitriptyline was preferred for patients with mild anxiety and depression (Table $1 S$ ).

The mean reductions in headache frequency and confidence intervals are reported in Table 4 and Table 2S. Most of the patients experienced a reduction in headache frequency of less than $50 \%$, with a slight increase in patients with a favorable outcome in the group treated with flunarizine (Table 5; Fig. 2). The exclusion from the analysis of patients with FM comorbidity, which could have influenced the choice of drugs, did not substantially change the percent change in responders (odds ratio: 0.94, p: 0.56), except for the lack of statistical significance for the calcium channel blocker effect (Table 3S). One hundred eighty $\mathrm{CM}$ patients with associated $\mathrm{MOH}$ discontinued the previous symptomatic drug, instead using the suggested therapy (triptans). One hundred fifty-five CM patients persisted as chronic, the remaining CM patients shifted to a diagnosis of episodic migraine, and in all of these patients, the diagnosis of $\mathrm{MOH}$ was not confirmed. The 40 remaining patients continued to use NSAIDs in excess, and the diagnosis of CM with $\mathrm{MOH}$ was confirmed.

The MANOVA comparing secondary outcome variables among different treatments and migraine subtypes showed a general improvement at the 3-month followup, which was not different among the preventive treatments and migraine diagnoses. The within-subject analysis showed significant reductions in headache intensity and allodynia in all treated patients (Table 6).

The multiple regression analysis showed that a lower allodynia score and a lower frequency of headache at baseline predicted a favorable outcome with at least a $50 \%$ frequency reduction (Table 7 , Table 4S; Fig. 3). The relationship between allodynia score and headache frequency was confirmed for antiepileptics, while in the group treated with antidepressants, a lower allodynia score and a lower headache intensity were associated with a better outcome (Table 5S). The multiple regression analysis did not show relevant results for the groups treated with the other drugs.

Comorbidity with FM and the presence of allodynia were associated with a lower number of patients with a good outcome, while gender had no effect on drug efficacy (Table 8).

\section{Discussion}

This observational retrospective cohort study tested the effects of preventive treatments in a population of migraine patients visiting a tertiary headache center. 
Table 1 Demographic and clinical data of migraine patients

\begin{tabular}{|c|c|c|c|c|c|c|c|}
\hline & & & Mean & SEM & $95 \% \mathrm{Cl}$ & & Post hoc (Bonferroni) \\
\hline & & cases & & & Lower & Upper & \\
\hline age & $\mathrm{MO}$ & $176 \mathrm{M} ; 471 \mathrm{~F}$ & 37.49 & 0.52 & 36.46 & 38.51 & Vs CM p $<0.001$ \\
\hline $\begin{array}{l}\text { ANOVA } \\
\text { F: } 9.08, P<0.0001\end{array}$ & MA & $3 \mathrm{M} ; 9 \mathrm{~F}$ & 28.55 & 3.91 & 20.86 & 36.23 & Vs CM p 0.005 \\
\hline & $\mathrm{MO}+\mathrm{MA}$ & $17 \mathrm{M} ; 39 \mathrm{~F}$ & 35.91 & 1.89 & 32.20 & 39.63 & Vs CM p 0.009 \\
\hline & CM & $78 \mathrm{M} ; 218 \mathrm{~F}$ & 40.94 & 0.79 & 39.40 & 42.49 & \\
\hline migraine duration & MO & & 15.53 & 0.47 & 14.62 & 16.45 & n.s. \\
\hline $\begin{array}{l}\text { ANOVA } \\
\text { F: } 1.44, P 0.22\end{array}$ & MA & & 11.27 & 3.49 & 4.42 & 18.12 & \\
\hline & $\mathrm{MO}+\mathrm{MA}$ & & 16.74 & 1.69 & 13.43 & 20.06 & \\
\hline & CM & & 16.70 & 0.70 & 15.32 & 18.08 & \\
\hline headache frequency & $\mathrm{MO}$ & & 9.61 & 0.27 & 9.08 & 10.13 & Vs CM $p<0.001$ \\
\hline $\begin{array}{l}\text { ANOVA } \\
\text { F: } 238.39, P<0.0001\end{array}$ & MA & & 6.82 & 2.00 & 2.90 & 10.74 & Vs CM $p<0.001$ \\
\hline & $\mathrm{MO}+\mathrm{MA}$ & & 9.24 & 0.97 & 7.35 & 11.14 & Vs CM $p<0.001$ \\
\hline & CM & & 22.26 & 0.40 & 21.47 & 23.05 & \\
\hline MIDAS & $\mathrm{MO}$ & & 25.62 & 1.70 & 22.29 & 28.95 & Vs CM $p<0.001$ \\
\hline $\begin{array}{l}\text { ANOVA } \\
\text { F: } 27.93, p<0.0001\end{array}$ & MA & & 18.82 & 12.68 & -6.06 & 43.70 & Vs CM p 0.048 \\
\hline & $\mathrm{MO}+\mathrm{MA}$ & & 20.77 & 6.13 & 8.73 & 32.80 & Vs CM p $<0.001$ \\
\hline & CM & & 52.99 & 2.55 & 47.99 & 58.00 & \\
\hline headache intensity (0-100 VAS) & $\mathrm{MO}$ & & 8.74 & 0.05 & 8.65 & 8.83 & Vs CM p 0.007 \\
\hline $\begin{array}{l}\text { ANOVA } \\
\text { F: } 4.67, \mathrm{p} 0.005\end{array}$ & MA & & 8.82 & 0.34 & 8.14 & 9.49 & \\
\hline & $\mathrm{MO}+\mathrm{MA}$ & & 9.09 & 0.17 & 8.76 & 9.41 & \\
\hline & CM & & 9.04 & 0.07 & 8.90 & 9.17 & \\
\hline Allodynia & $\mathrm{MO}$ & & 2.67 & 0.08 & 2.51 & 2.82 & n.s. \\
\hline & MA & & 1.82 & 0.60 & 0.64 & 3.00 & \\
\hline & $\mathrm{MO}+\mathrm{MA}$ & & 3.15 & 0.29 & 2.58 & 3.72 & \\
\hline & CM & & 3.01 & 0.12 & 2.78 & 3.25 & \\
\hline SAS & $\mathrm{MO}$ & & 36.68 & 0.37 & 35.97 & 37.40 & Vs CM $p<0.001$. \\
\hline F:8 & MA & & 35.64 & 2.75 & 30.24 & 41.04 & \\
\hline & $\mathrm{MO}+\mathrm{MA}$ & & 36.04 & 1.28 & 33.53 & 38.55 & Vs CM p 0.035 \\
\hline & CM & & 39.88 & 0.55 & 38.81 & 40.95 & \\
\hline SDS & $\mathrm{MO}$ & & 35.28 & 0.38 & 34.52 & 36.03 & Vs CM $p<0.001$ \\
\hline נו & MA & & 30.36 & 2.90 & 24.68 & 36.05 & Vs CM: p 0.023 \\
\hline & $\mathrm{MO}+\mathrm{MA}$ & & 34.82 & 1.35 & 32.18 & 37.47 & Vs CM p 0.03 \\
\hline & CM & & 38.94 & 0.57 & 37.82 & 40.07 & \\
\hline
\end{tabular}

MO migraine without aura, MA migraine with aura, $C M$ chronic migraine. Frequency: average number of days with headache per month over the 3 months preceding the first visit. SAS Zung anxiety score. SDS Zung depression score. The results of ANOVAs $(D F=3)$ and post hoc Bonferroni tests are reported

The main results consisted of a mild effect of treatments on headache frequency, with a less than $50 \%$ reduction in most cases, as well as on migraine-related disability and general quality of life. Flunarizine was prescribed for patients with a lower headache frequency, rather than antiepileptics and antidepressants, and showed slight superiority in terms of therapeutic efficacy. Amitriptyline was preferred for patients with higher anxiety and depression scores.
The absence of or less severe allodynia predicted a better outcome, while comorbidity with fibromyalgia was associated with a reduced therapeutic effect.

\section{General considerations regarding headache populations}

These real-life data show that in our tertiary headache center in South Italy, most of the patients suffered medium-high frequency migraine, they were not previously treated with preventive drugs, and only a minority 
Table 2 Preventive drugs used by migraine patients

\begin{tabular}{|c|c|c|c|c|c|c|}
\hline \multirow[t]{2}{*}{ Drugs } & \multirow[t]{2}{*}{ Daily Dosages } & \multicolumn{2}{|c|}{ Migraine diagnosis } & \multirow[b]{2}{*}{$\mathrm{MA}+\mathrm{MO}$} & \multirow[b]{2}{*}{ CM } & \multirow[t]{2}{*}{ Tota } \\
\hline & & $\mathrm{MO}$ & MA & & & \\
\hline Beta-blockers & Propranolol: 80-160 mg; atenolol: 50-100 mg & 36 & 0 & 2 & 7 & 45 \\
\hline calcium channel blockers & Flunarizine: $5 \mathrm{mg}$ & 139 & 2 & 9 & 15 & 165 \\
\hline Antidepressants & Amitriptyline: 10-25 mg & 245 & 5 & 17 & 158 & 425 \\
\hline Integrators & Magnesium: 300-400 mg & 57 & 0 & 4 & 3 & 64 \\
\hline Antiepileptics & Topiramate: 50-100 & 149 & 5 & 22 & 100 & 276 \\
\hline Sartans & Candesartan: 8-16 mg & 21 & 0 & 2 & 13 & 36 \\
\hline Total & & 647 & 12 & 56 & 296 & 1011 \\
\hline
\end{tabular}

of them used triptans. An Italian study [3] showed that only a minority of patients using triptans and that qualified for prophylaxis used preventive drugs. Therefore, they did not have access to headache specialists or centers, minimally complied with the prescribed treatment, or withdrew because of adverse events. Our impression is that most of the patients were referred to our center for medium-high frequency migraine that was previously underestimated, though it warranted preventive treatment and triptan prescription. This finding is in line with the results of a study conducted 10 years ago with data from 10 Italian headache centers, which demonstrated that only $26.8 \%$ of 2675 patients attending the centers had previously received a diagnosis of migraine [15].

Of the total number of patients free from other CNS drugs or relevant comorbidities, approximately 1000 were lost to follow-up, in accordance with previous studies $[16,17]$. Poor adherence is recognized as the major factor impairing the efficacy of migraine prophylactics [18]. More than 500 patients withdrew because of adverse events, which confirms that low compliance may be attributed to side effects and the low efficacy of prescribed drugs.

In our selected migraine sample, only a minority suffered medium-high-frequency migraine with aura, which

Table 3 Frequency of headache at baseline in the different drug groups. ANOVA with drug as a factor: $F=20.54, p<0.0001$. Bonferroni with antiepileptics and antidepressants vs betablockers, calcium channel blockers and integrators: $p<0.001$. Sartans vs integrators: $p<0.05$

\begin{tabular}{lllll}
\hline Drugs & Mean & SEM & & \multicolumn{2}{l}{$95 \% \mathrm{Cl}$} & \\
\cline { 5 - 6 } & & & Lower & Upper \\
\hline Beta-blockers & 9.46 & 1.25 & 7.01 & 11.90 \\
Calcium channel blockers & 9.45 & 0.65 & 8.17 & 10.73 \\
Antidepressants & 14.64 & 0.41 & 13.84 & 15.43 \\
Integrators & 7.30 & 1.05 & 5.25 & 9.36 \\
Antiepileptics & 15.24 & 0.50 & 14.25 & 16.23 \\
Sartans & 12.94 & 1.40 & 10.21 & 15.68 \\
\hline
\end{tabular}

is in accord with data for the general population [19, 20].

The duration of migraine was very long in our sample, even in several patients without previous preventive treatments. Patients with $\mathrm{CM}$ were naïve to treatment, although their clinical picture was obviously more severe than that of the episodic migraine groups, with more severe disability and higher anxiety and depression scores. It is thus conceivable that transformation to chronic migraine recently occurred, although most of these patients had a history of drug abuse, according to current knowledge [21].

The neurologists treated patients in accordance with Italian guidelines [2]. Sodium valproate was reserved as a second-line approach, as its use is off-label in Italy. The choice of antidepressants and antiepileptics as a first-line therapy was reserved for patients with more severe and chronic migraine, according to previous studies $[21,22]$. The use of magnesium in 64 patients as a preventive treatment deserves proper discussion. Nutraceutics have low efficacy in migraine prophylaxis, and their level of evidence is very low [23, 24]. Moreover, migraine patients are not confident in the use of CNS-targeting drugs [25], and sometimes they do not agree with this approach. The use of magnesium and other nutraceutics is frequent in clinical practice [23]. This is why we decided to include patients with magnesium treatment in the final analysis. According to current national guidelines [2], candesartan has a recommendation level of 3 , but clinicians used it in only a small number of patients. A review of clinical records revealed that patients had mild but underestimated and uncontrolled hypertension and contraindications to the use of beta-blockers. Considering that this situation may occur in clinical practice, we also included this group in the final analysis.

\section{Effects of preventive treatments on migraine frequency}

There was only a mild effect on headache frequency in the 3 months following preventive drug prescription, in accord with the findings of previous studies based on indirect evidence $[3,16,21]$. The failure of the first 
Table 4 Mean (M) and standard deviation (SD) of the percent reduction in migraine frequency for patients with MO: migraine without aura, MA: migraine with aura, and CM: chronic migraine

\begin{tabular}{|c|c|c|c|c|}
\hline Drugs & Migraine diagnosis & $\begin{array}{l}M \\
(\%)\end{array}$ & DS & Case number \\
\hline \multirow[t]{4}{*}{ Beta-blockers } & $\mathrm{MO}$ & 23.31 & 63.17 & 36 \\
\hline & $\mathrm{MO}+\mathrm{MA}$ & 12.50 & 17.68 & 2 \\
\hline & $C M$ & 56.67 & 40.60 & 7 \\
\hline & Total & 28.02 & 59.72 & 45 \\
\hline \multirow[t]{5}{*}{ calcium channel blocker } & MO & 34.04 & 40.41 & 139 \\
\hline & MA & 56.25 & 61.87 & 2 \\
\hline & $\mathrm{MO}+\mathrm{MA}$ & 44.40 & 38.54 & 9 \\
\hline & $C M$ & 25.06 & 29.09 & 15 \\
\hline & Total & 34.05 & 39.51 & 165 \\
\hline \multirow[t]{5}{*}{ Antidepressants } & MO & 26.93 & 43.49 & 245 \\
\hline & MA & 20.45 & 36.63 & 5 \\
\hline & $\mathrm{MO}+\mathrm{MA}$ & 22.09 & 56.62 & 17 \\
\hline & $C M$ & 31.05 & 32.88 & 157 \\
\hline & Total & 28.18 & 40.37 & 424 \\
\hline \multirow[t]{4}{*}{ Integrators } & $\mathrm{MO}$ & 25.88 & 54.23 & 57 \\
\hline & $\mathrm{MO}+\mathrm{MA}$ & 33.33 & 22.82 & 4 \\
\hline & $C M$ & 27.92 & 24.25 & 3 \\
\hline & Total & 26.44 & 51.59 & 64 \\
\hline \multirow[t]{5}{*}{ Antiepileptics } & $\mathrm{MO}$ & 18.51 & 56.06 & 149 \\
\hline & MA & 56.59 & 34.73 & 5 \\
\hline & $\mathrm{MO}+\mathrm{MA}$ & 22.87 & 58.33 & 22 \\
\hline & $C M$ & 29.97 & 32.88 & 101 \\
\hline & Total & 23.70 & 49.05 & 276 \\
\hline \multirow[t]{4}{*}{ Sartans } & $\mathrm{MO}$ & 22.35 & 57.85 & 21 \\
\hline & $\mathrm{MO}+\mathrm{MA}$ & 25.00 & 35.36 & 2 \\
\hline & $C M$ & 16.45 & 23.65 & 13 \\
\hline & Total & 20.37 & 46.36 & 36 \\
\hline \multirow[t]{5}{*}{ Total } & $\mathrm{MO}$ & 26.07 & 48.84 & 647 \\
\hline & MA & 41.47 & 40.24 & 12 \\
\hline & $\mathrm{MO}+\mathrm{MA}$ & 26.54 & 50.79 & 56 \\
\hline & $C M$ & 30.31 & 32.64 & 295 \\
\hline & Total & 27.52 & 44.75 & 1011 \\
\hline
\end{tabular}

ANOVA with drugs as a factor: $F=0.47, p=0.81$; with migraine diagnosis as a factor: $F=0.73, p=0.53$; with drugs $\mathrm{x}$ migraine diagnosis: $F=0.70, p=0.73$

Table 5 Number of patients with favorable (reduction in headache frequency $>50 \%)$ and unfavorable $(<50 \%)$ outcomes after 3 months of treatment. The odds ratio was computed for a single drug compared with the remaining population

\begin{tabular}{|c|c|c|c|c|c|c|c|}
\hline & Beta-blockers & Calcium channel blockers & Antidepressants & Integrators & Antiepileptics & Sartans & Total \\
\hline$<50 \%$ & 28 & 98 & 288 & 40 & 196 & 27 & 677 \\
\hline \multirow[t]{2}{*}{$>50 \%$} & 17 & 67 & 137 & 24 & 80 & 9 & 334 \\
\hline & 45 & 165 & 425 & 64 & 276 & 36 & 1011 \\
\hline Odds ratio & 1.23 & 1.48 & 0.93 & 1.23 & 0.77 & 0.66 & \\
\hline $95 \% \mathrm{Cl}$ & 0.67 to 2.30 & 1.05 to 2.08 & 0.71 to 1.2 & 0.71 to 2.08 & 0.57 to 1.046 & 0.3 to 1.4 & \\
\hline z statistic & 0.69 & 2.25 & 0.461 & 0.78 & 1.67 & 1.037 & \\
\hline Sig. level & $P=0.48$ & $P=0.02$ & $P=0.64$ & $P=0.43$ & $P=0.09$ & $P=0.29$ & \\
\hline
\end{tabular}




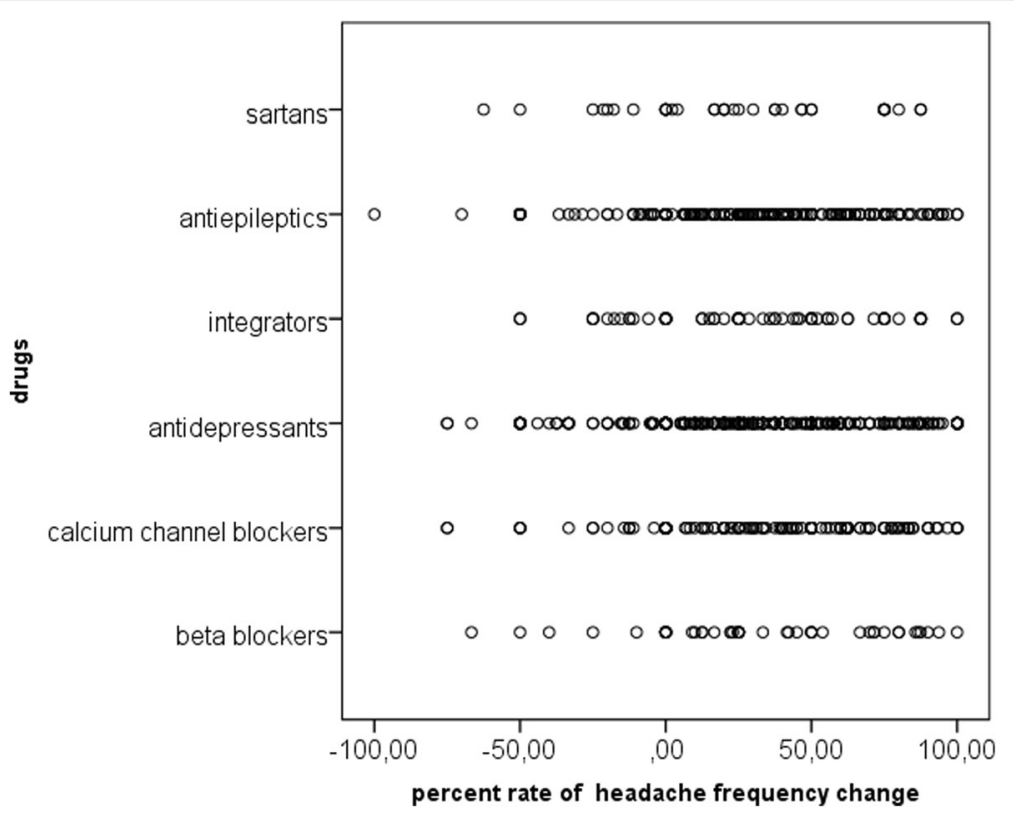

Fig. 2 Representation of the percent change in headache frequency for single cases

preventive attempt was also confirmed in $80 \%$ of patients in a large population with migraine (9856 patients) interviewed about the burden of the disease [26]. This suggests that there is a difference between randomized controlled trials (RCTs) and real life. Moreover, relevant RCTs are limited, and they were conducted many years ago in small patient series [2]. It is thus not surprising that magnesium was not inferior in efficacy when compared to recommended drugs, as its mild effect confirmed the results of RCTs [23]. In addition, candesartan exerted a slight effect on headache frequency that was not inferior to that of other drugs [27]. The comparison among groups with different case numbers is quite unreliable from a statistical point of view (see paragraph below), but it could support the general impression of weak action of all the prescribed drugs against headache frequency.

Flunarizine at a $5 \mathrm{mg}$ dosage was more efficacious than other drugs in treating headache frequency [28], though the statistical relevance vanished with the removal of patients with FM comorbidity. Moreover, clinicians prescribed flunarizine to patients with a lower frequency of migraine, which is a factor predisposing them to a better outcome. Patients reported the use of triptans in the majority of cases, which could be partly responsible for the reduction in headache intensity. Chronic patients with NSAID overuse were also invited to shift to triptans. In any case, the majority of patients remained chronic with the overuse of triptans due to the weak effect of preventive treatments.

Table 6 Mean (M) and standard deviation (SD) of secondary outcome variables in 1011 migraine patients at baseline and after 3 months under preventive treatment (demographic data are reported in Table 1)

\begin{tabular}{|c|c|c|c|c|c|c|}
\hline Condition & & MIDAS & VAS & ALLODYNIA & PH SF36 & MH SF36 \\
\hline \multirow[t]{2}{*}{ Baseline } & $M$ & 33.30 & 8.82 & 2.81 & 36.59 & 38.67 \\
\hline & SD & 43.97 & 1.16 & 2.00 & 8.93 & 8.75 \\
\hline \multirow[t]{2}{*}{ Follow-up } & $M$ & 21.74 & 8.30 & 2.40 & 38.10 & 39.48 \\
\hline & SD & 31.22 & 1.46 & 1.98 & 8.74 & 8.99 \\
\hline \multirow[t]{3}{*}{ Within-subject ANOVA } & $F$ & 2.93 & 9.39 & 3.39 & 1.14 & 1.37 \\
\hline & DF & 2 & 2 & 2 & 2 & 2 \\
\hline & $P$ & 0.053 & $<0.001$ & 0.034 & 0.31 & 0.25 \\
\hline
\end{tabular}

MANOVA, condition (baseline vs follow-up): $\mathrm{F}$ (Roy square) $=5.12, \mathrm{DF}=5, p<0.0001$; condition vs drug: $F=0.64, \mathrm{DF}=5, P=0.69$; condition vs migraine type: $\mathrm{F}=$ $1.83, \mathrm{DF}=5 p=0.1$; condition vs drug vs migraine type: $F=0.55, \mathrm{DF}=12, p=0.88$. The within-subject ANOVA results are reported $\mathrm{PH}$ physical Health score SF36, MH mental health score SF36 
Table 7 Multiple regression analysis of the change in frequency at follow-up in 1011 migraine patients

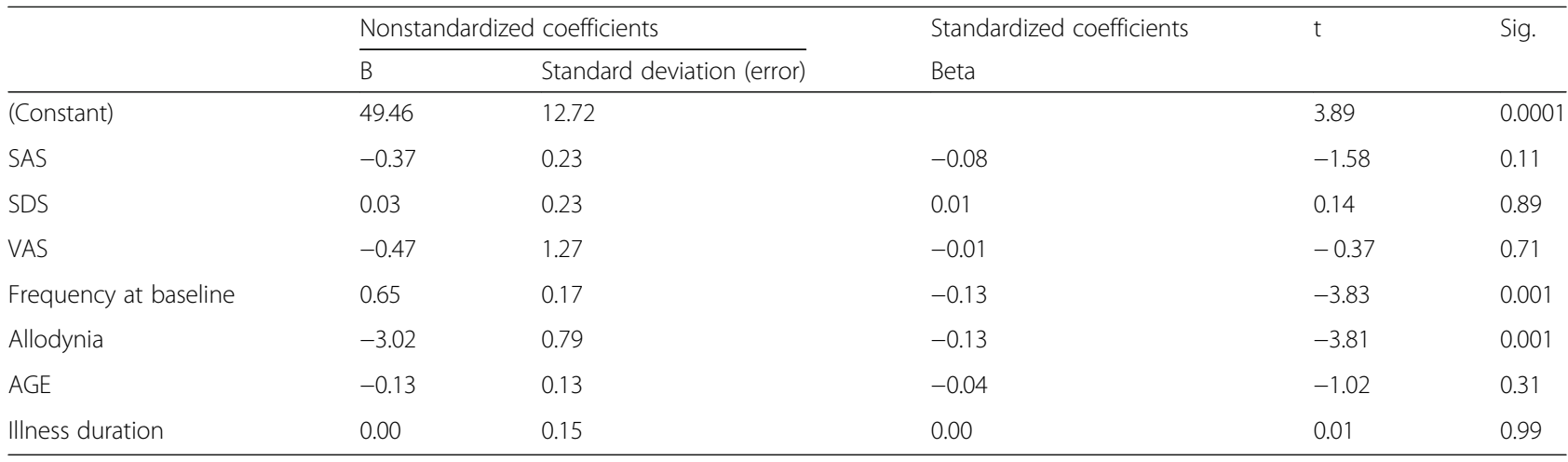

SAS Zung anxiety score

SDS Zung depression score

\section{Effects of preventive treatments on other clinical variables}

The general improvement of migraine-related disability, quality of life, headache intensity and allodynia was independent of the drug and type of migraine. Considering the single variables, the intensity of headache and allodynia changed in a relevant way, an effect attributable to the preventive treatments and probably to the use of triptans. An effect of antiepileptics and antidepressants on allodynia was also reported in previous studies [29]. An Italian longitudinal study on migraine evolution over 3 months of observation reported an evident trend toward improvement in disability and social activity, independent of the use of preventive treatments [30]. The slight improvement of the evaluated clinical features can be attributed partly to spontaneous evolution in patients during continued care and partly to an effect of preventive and acute treatments.

\section{Predictor variables}

Low frequency of migraine and reduced expression or absence of allodynia symptoms at baseline predicted a better effect of preventive treatments in all patients. Studies focusing on factors predicting the effects of acute treatments show that allodynic patients have a worse response to triptans [31]. A predictive role of

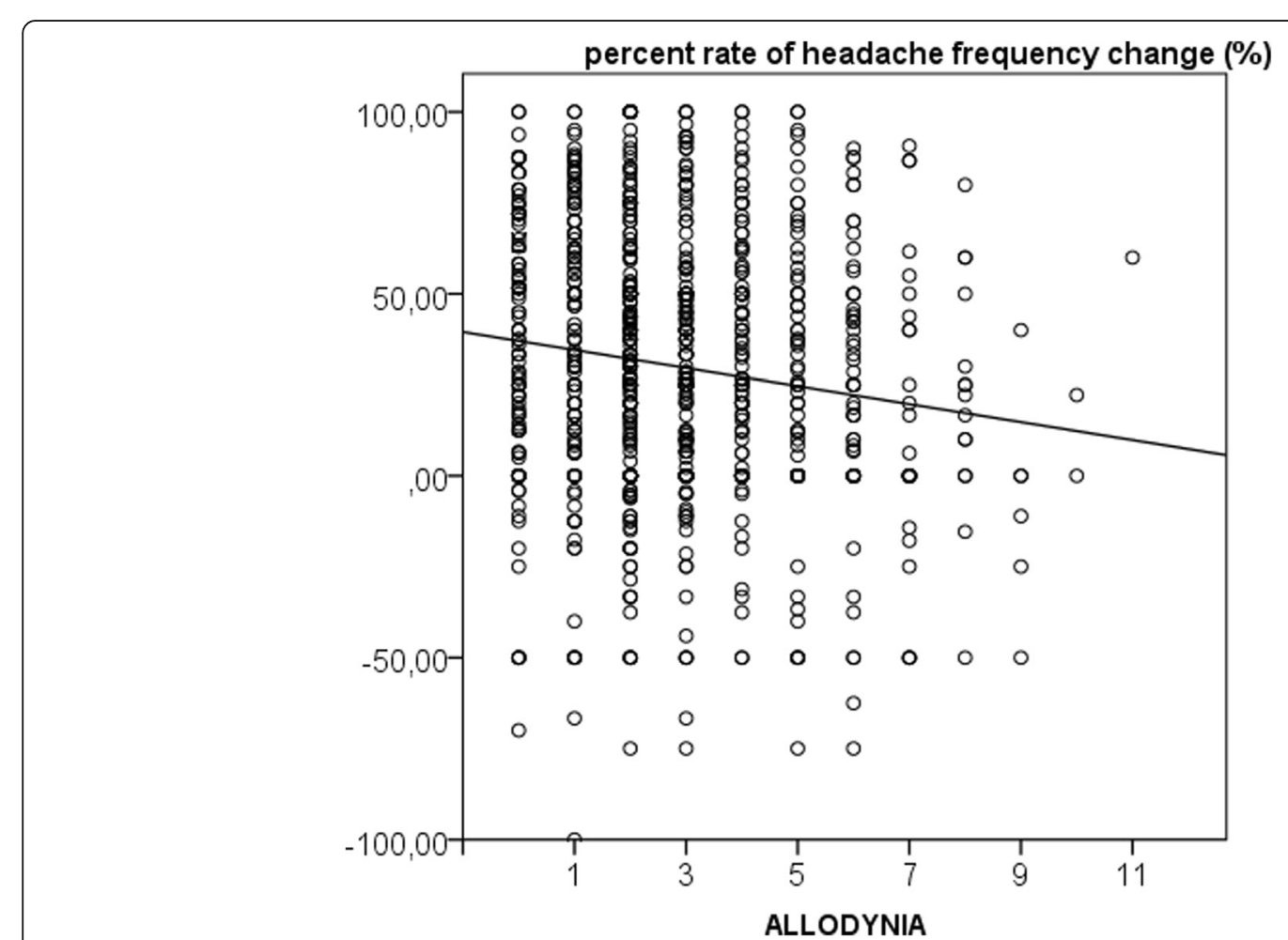

Fig. 3 Linear regression analysis between the rate of headache frequency change and allodynia at baseline 
Table 8 Effect of fibromyalgia (FM) comorbidity, gender and allodynia on the primary outcome (50\% headache frequency reduction)

\begin{tabular}{|c|c|c|c|c|c|c|c|}
\hline & & Outcom & & Odds ratio & $95 \% \mathrm{Cl}$ & z statistic & Significance level \\
\hline & & $<50 \%$ & $\geq 50 \%$ & & & & \\
\hline FM comorbidity & no & 571 & 299 & 1.58 & 1.05 to 2.38 & 2.2 & $P=0.02$ \\
\hline & yes & 106 & 35 & & & & \\
\hline Gender & M & 180 & 94 & 1.08 & 0.8 to 1.44 & 0.523 & $P=0.6$ \\
\hline & $\mathrm{F}$ & 497 & 240 & & & & \\
\hline Allodynia & No & 73 & 67 & 0.5 & 0.35 to 0.72 & 3.67 & $P=0.0002$ \\
\hline & Yes & 594 & 277 & & & & \\
\hline
\end{tabular}

allodynia was observed in the groups of patients treated with antidepressants and antiepileptics, which included a reliable number of patients. Anxiety and depression at baseline, which were more highly expressed in the CM group, were not associated with a worse efficacy of treatments against headache frequency. We excluded cases with previously documented psychiatric diseases. Considering that scores $\geq 50$ for the depression scale and $\geq 45$ for the anxiety scale $[12,13]$ indicate relevant symptoms, our patients presented with scores within normal ranges; however, the scores were higher in our CM patients than in the other participants. Basal anxiety and depression scores do not seem relevant for the final effects of drugs and certainly are not relevant in patients without psychiatric disorders.

Gender was also unrelated to the effect of preventive drugs. Males accounted for $27 \%$ of the total selected population, which is consistent with migraine representation in a sample of the Italian population [32]. Previous studies reported that males have better compliance with treatments than females, though the effect of sex on treatment efficacy was not evaluated [33].

Comorbidity with FM was also associated with a reduced effect of preventive drugs on headache frequency. Most migraine patients with associated FM used amitriptyline, which may be a good therapeutic option when this comorbidity is present [14]. In previous studies, we observed an association between FM and more severe migraine [14]. The present results also confirmed a minor response to preventive treatments. FM patients generally have a weak response to different treatments, indicating the need for an individualized therapeutic approach. In migraine patients with FM comorbidity, central sensitization is a predominant phenomenon, causing a diffusion of pain in somatic sites [14]. In light of the present study, we suggest that the clinical expression of central sensitization phenomena such as allodynia and FM comorbidity predicts a worse response to preventive treatment.

\section{Study limitations}

This observational retrospective study has several limitations.

The sample size for the first outcome variable was reliable for the entire group and for patients treated with antidepressants, while the case number was smaller for the other drugs. Moreover, in our opinion, the results could shed light on real-life situations.

Potential confusion and bias may have affected the final reliability of the data. We found the lack of information about the efficacy of symptomatic treatments particularly important, meaning that the reduction in allodynia and intensity of headache at follow-up cannot be assigned to triptans or preventive treatments.

We focused on fibromyalgia comorbidity, as our center has specific experience in the application of diagnostic criteria. Other comorbidities, such as hypertension or obesity, lifestyle, physical inactivity, habits, smoking, or even professions, could affect the outcome of treatments, but we decided to focus on the main clinical and demographic aspects in selected patients during their first preventive approach, reserving a global evaluation of these factors for further analyses. In addition, the consideration of FM comorbidity may have influenced the choice of drugs, though the removal of such patients did not substantially change the percentage of responders.

The study is observational and lacks a control population, which would be useful for dissecting the effect of drugs from spontaneous evolution.

\section{Conclusions}

A mild effect of current preventive treatments on headache frequency and disability emerged from the present data. The number of patients lost to follow-up or who dropped out because of adverse events was large and confirms that the preventive approach to migraine treatment is currently inefficacious and unwelcome, even in tertiary headache centers. The low number of chronic patients reverting to the episodic form by the threemonth follow-up confirms this impression. No drug 
demonstrated high efficacy, except for flunarizine, which was prescribed to less affected patients. Potential useful indicators for the use of current first-line preventive drugs may be a low frequency of migraine and the absence of allodynia and other central sensitization symptoms, such as fibromyalgia. These results support the early use of more recent treatments such as botulinum toxin or CGRP antagonists in naïve patients with medium-severe headache frequency and allodynia, in contrast to the general trend of offering these as firstline preventive drugs for resistant patients.

\section{Supplementary information}

Supplementary information accompanies this paper at https://doi.org/10. 1186/s12883-020-01839-5.

\section{Additional file 1.}

Additional file 2: Table S1. Zung Anxiety and Depression Scores at baseline in migraine patients submitted to different preventive treatments. Results of MANOVA analysis F $5.49 p<0.0001$. Post hoc Bonferroni test: antidepressant vs Calcium Channel blockers and integrators: $p<0.01$. Table S2. 95\% Confidence Intervals values for change of headache frequency. Table S3. Number of patients without FM comorbidity with favorable (reduction of headache frequency $>50 \%$ ) and unfavorable $(<50 \%)$ outcome after 3 months. The odd ratio was computed for single drugs, compared with the remaining population.

Table S4. Details of multiple regression analysis for change of headache frequency. Table S5. Multiple regression analysis between clinical features at baseline and change of headache frequency in subgroups of migraine patients sas: Zung anxiety score; sds: Zung depression score.

\section{Abbreviations}

MA: Migraine with aura; MO: Migraine without aura; CM: Chronic migraine; FM: Fibromyalgia; SDS: Self-rating depression scale; SAS: Self-rating anxiety scale

\section{Acknowledgments}

Not applicable.

\section{Consent to publication}

Marina de Tommaso confirms that she had full access to all the data in the study and had final responsibility for the decision to submit for publication. Consent for publication of identifying images or other personal or clinical details of participants that compromise anonymity is not applicable.

\section{Authors' contributions \\ M. D.: patient evaluation, database construction, data analysis, study design. E. V.: patient evaluation and selection, study design. S. Q.: patient evaluation and selection, study design. G. L.: patient evaluation and selection, manuscript editing. M. d. T.: study design, data analysis, manuscript preparation and editing. All authors have approved the submitted version and have agreed both to be personally accountable for the author's own contributions and to ensure that questions related to the accuracy or integrity of any part of the work, even ones in which they were not personally involved, were appropriately investigated, resolved, and the resolution documented in the literature}

\section{Funding}

No funder supported the study.

\section{Availability of data and materials}

The datasets used and/or analyzed during the current study are available from the corresponding author upon reasonable request.

\section{Ethics approval and consent to participate}

The local Ethics Committee of Policlinico General Hospital approved the use of the electronic database, and patients signed an informed consent form about the inclusion of their data and use for scientific purposes.

\section{Competing interests}

No authors declare any conflicts of interest.

Received: 16 April 2020 Accepted: 23 June 2020

Published online: 27 June 2020

\section{References}

1. World Health Organization (WHO). Disease burden and mortality estimates. 2018.http://who.int/healthinfo/global_burden_disease/estimates/en/index1. html. Accessed 20 May 201.

2. Sarchielli P, Granella F, Prudenzano MP, et al. Italian guidelines for primary headaches: 2012 Revised version. J Headache Pain. 2012;13(Suppl 2):S31-70.

3. Piccinni C, Cevoli S, Ronconi G, et al. A real-world study on unmet medical needs in triptan-treated migraine: prevalence, preventive therapies and triptan use modification from a large Italian population along two years. J Headache Pain. 2019:20(1):74.

4. Ford JH, Schroeder K, Buse DC, et al. Predicting initiation of preventive migraine medications: exploratory study in a large U.S. medical claims database. Curr Med Res Opin. 2020;36(1):51-614

5. Valade $D$, Lantéri-Minet $M$, Radat $F$, et al. Clinical determinants of migraine preventive treatment: contribution of SMILE, an observational survey of primary care migraine management in France. Cephalalgia. 2010;30(10): 1207-13.

6. Edvinsson L, Haanes KA, Warfvinge $K$, Krause DN. CGRP as the target of new migraine therapies - successful translation from bench to clinic. Nat Rev Neurol. 2018;14(6):338-50.

7. de Tommaso M, Brighina F, Delussi M. Effects of Botulinum toxin a on Allodynia in chronic migraine: an observational open-label two-year study. Eur Neurol. 2019:81(1-2):37-46.

8. Headache Classification Subcommittee of International headache Society. The international classification of headache disorders, 2nd edition. Cephalalgia. 2004;24(Suppl. 1):24-36.

9. Headache Classification Committee of the International Headache Society. (IHS). The international classification of headache disorders, 3rd edition. Cephalalgia. 2018;38(1):1-211.

10. D'Amico D, Mosconi P, Genco S, Usai S, Prudenzano AM, Grazzi L, Leone M, Puca FM, Bussone G. The migraine disability assessment (MIDAS) questionnaire: translation and reliability of the Italian version. Cephalalgia. 2001;21:947-52

11. Hays RD, Stewart A. Sleep measures. In: Stewart A, Ware J, editors Measuring functioning and well-being: the medical outcomes study approach. Durham: Duke University Press; 1992. p. 235-59.

12. Zung WW. A self-rating depression scale. Arch Gen Psychiatry. 1965;12:63-70.

13. Zung WW. A rating instrument for anxiety disorders. Psychosomatics. 1971; 12:371-9.

14. de Tommaso M, Sciruicchio V. Migraine and central sensitization: clinical features, Main comorbidities and therapeutic perspectives. Curr Rheumatol Rev. 2016;12(2):113-26

15. Cevoli S, D'Amico D, Martelletti $P$, et al. Underdiagnosis and undertreatment of migraine in Italy: a survey of patients attending for the first time 10 headache centres. Cephalalgia. $2009 ; 29(12): 1285-93$.

16. Ford JH, Jackson J, Milligan G, Cotton S, Ahl J, Aurora SK. A real-world analysis of migraine: a cross-sectional study of disease burden and treatment patterns. Headache. 2017;57(10):1532-44.

17. Hepp Z, Dodick DW, Varon SF, Gillard P, Hansen RN, Devine EB. Adherence to oral migraine-preventive medications among patients with chronic migraine. Cephalalgia. 2015;35(6):478-88.

18. Steiner TJ, Jensen R, Katsarava Z, et al. Aids to management of headache disorders in primary care (2nd edition) : on behalf of the European Headache Federation and Lifting The Burden: the Global Campaign against Headache. J Headache Pain. 2019;20(1):57.

19. Russell MB, Rasmussen BK, Thorvaldsen P, Olesen J. Prevalence and sex-ratio of the subtypes of migraine. Int J Epidemiol. 1995;24:612-7.

20. Manzoni GC, Torelli P. Migraine with and without aura: a single entity? Neurol Sci. 2008;29(Suppl 1):S40-3. 
21. Agostoni EC, Barbanti P, Calabresi P, et al. Current and emerging evidencebased treatment options in chronic migraine: a narrative review. J Headache Pain. 2019;20(1):92.

22. García-Azorin D, Santos-Lasaosa S, Gago-Veiga AB, Viguera Romero J, Guerrero-Peral AL. Real world preventative drug management of migraine among Spanish neurologists. J Headache Pain. 2019;20(1):19.

23. Tepper SJ. Nutraceutical and Other Modalities for the Treatment of Headache. Continuum (Minneap Minn). 2015;21 (4 Headache):1018-31.

24. Chiu HY, Yeh TH, Huang YC, Chen PY. Effects of intravenous and Oral magnesium on reducing migraine: a meta-analysis of randomized controlled trials. Pain Physician. 2016;19(1):E97-E112.

25. Hepp Z, Bloudek LM, Varon SF. Systematic review of migraine prophylaxis adherence and persistence. J Manag Care Pharm. 2014;20(1):22-33.

26. Martelletti P, Schwedt TJ, Lanteri-Minet M, et al. My migraine voice survey: a global study of disease burden among individuals with migraine for whom preventive treatments have failed. J Headache Pain. 2018;19(1):115.

27. Dorosch T, Ganzer CA, Lin M, Seifan A. Efficacy of angiotensin-converting enzyme inhibitors and angiotensin receptor blockers in the preventative treatment of episodic migraine in adults. Curr Pain Headache Rep. 2019; 23(11):85.

28. Diener HC, Matias-Guiu J, Hartung E, Pfaffenrath V, Ludin HP, Nappi G, De Beukelaar F. Efficacy and tolerability in migraine prophylaxis of flunarizine in reduced doses: a comparison with propranolol $160 \mathrm{mg}$ daily. Cephalalgia. 2002;22(3):209-21.

29. Misra UK, Kalita J, Bhoi SK. Allodynia in migraine: clinical observation and role of prophylactic therapy. Clin J Pain. 2013;29(7):577-82.

30. Raggi A, Leonardi M, Bussone G, D'Amico D. A 3-month analysis of disability, quality of life, and disease course in patients with migraine. Headache. 2013;53(2):297-309.

31. Lipton RB, Munjal S, Buse DC, et al. Allodynia is associated with initial and sustained response to acute migraine treatment: results from the American Migraine Prevalence and Prevention study. Headache. 2017;57(7):1026-40.

32. Ferrante T, Castellini P, Abrignani G, et al. The PACE study: past-year prevalence of migraine in Parma's adult general population. Cephalalgia. 2012:32(5):358-65.

33. Lipton RB, Munjal S, Alam A, et al. Migraine in America symptoms and treatment (MAST) study: baseline study methods, treatment patterns, and gender differences. Headache. 2018;58(9):1408-26.

\section{Publisher's Note}

Springer Nature remains neutral with regard to jurisdictional claims in published maps and institutional affiliations.

Ready to submit your research? Choose BMC and benefit from:

- fast, convenient online submission

- thorough peer review by experienced researchers in your field

- rapid publication on acceptance

- support for research data, including large and complex data types

- gold Open Access which fosters wider collaboration and increased citations

- maximum visibility for your research: over $100 \mathrm{M}$ website views per year

At BMC, research is always in progress.

Learn more biomedcentral.com/submissions 